\title{
The Lifetime Prevalence and Factors Associated with Relapse Among Mentally Ill Patients at Jimma University Medical Center, Ethiopia: Cross Sectional Study
}

\author{
Liyew Agenagnew (i) Chalachew kassaw
}

Received: 2 May 2020/ Accepted: 27 June 2020/Published online: 20 July 2020

(C) The Author(s) 2020

\begin{abstract}
Relapse is a condition of getting back to illness after the recovery from illness. It results in stigma, high cost of treatments, and a decline in functionality both for patients and their families. It is common in mentally ill patients therefore this study attempted to assess lifetime prevalence and factors associated with relapse in a patient with mental illness. Institutional based cross-sectional study design was employed and simple random sampling techniques were used to select 178 study participants. Data were collected through face to face interviews by using a single item question to measure relapse. Data were entered by using Epi-data 3.1 software and exported to the statistical package for social science 22.0 software for analysis. Bivariate logistic regression analysis was conducted to see the association between dependent and independent variables and to identify significant variables associated with the outcome variable at $P<$ 0.05 multivariable logistic regression analysis was done. One hundred seventy-eight mentally ill patients have participated in the study that yields a response
\end{abstract}

\footnotetext{
L. Agenagnew ( $\square)$

Department of Psychiatry, Faculty of Medical Sciences, Institute of Health, Jimma University,

P.O. Box 378, Jimma, Ethiopia

e-mail: liyew2003@gmail.com

C. kassaw

Department of Psychiatry, College of Health Science,

Dilla University, P.O. Box 419, Dilla, Ethiopia

e-mail: 1234berekassa@gmail.com
}

rate of $100 \%$. From all $125(70.2 \%)$ of them had relapsed. Non adherance $(\mathrm{AOR}=6.35,95 \% \mathrm{CI}$, 2.524-15.852, $P<0.001)$, high disablity score (AOR $=3.728,95 \%$ CI, 1.434-9.687, $P=0.007$ ) and having single admission history $(\mathrm{AOR}=0.196$, 95\% CI, 0.050-0.761 $P=0.019$ ) were factors which indepedently associated with relapse of mentally ill patients. This study found more than two-thirds of patients had relapsed. Adherence to medication, functional disability, and having single admission were variables that predict the relapse of mentally ill patients.

Keywords Lifetime relapse - Mental illness · Outpatients service $\cdot$ Jimma University $\cdot$ Ethiopia

\section{Background}

Mental disorders have a high burden in all countries with huge effects on the health, social, human rights of individuals [1].

The gap between the need for treatment and its provision is wide all over the world because of health systems have not yet adequately responded to the burden of mental disorders, as a consequence, in low and middle-income countries, between 76 and $85 \%$ of people with mental disorders did not receive treatment [2]. 
By 2030, the cost to the global economy of all mental health problems could amount to $\$ 16$ trillion and now world health organizations give emphasis and work on it [3].

Relapse in mental illness is defined as deterioration or return in a patient's previous illness condition after a partial recovery and it is common in all types of mental disorders with different rate of relapse 52-92\% in schizophrenia [4], 50 to $90 \%$ in substance use disorders and $65 \%$ to $73 \%$ in bipolar disorder [5].

In most studies age, sex, education level, current employment status, engaging in religious activities, type of mental illness, early age onset of illness, duration of illness, co-morbidity of substance use, number of episode of illness, stigma, social support, poorer medication adherence, type of medication used, duration of stopping the medication, the previous number of hospitalization, the severity of symptoms and current functional status and stigma of patients were factors associated with relapse among mentally ill patients [4, 6-14].

Patients with mental illness considered reappearing of sign and symptoms as a sense of failure and hurt both patients and their relatives, moreover, it worsens treatment outcome, increase the number of admissions, and treatment costs, incapacitate the patients, which results to losses of productivity and income generation, lastly affects the economy of a country [15-18].

To address the growing rate of relapse among mentally ill patients different strategies were tried like improving the accessibility of mental health service, involving the family and community during patient treatment at hospital through teaching early warning signs of relapse and conditions which may potentially exacerbating of mental illness, like having poor sleep, loss or grief, conflict among loved ones, an unpleasant event such as a perceived failure, disappointment or criticism, alcohol, and other drug use, a change in the season, reproductive cycle, not following through treatment plan (such as not taking prescribed medications), and having other physical problems), strengthening self-support system among mentally ill patients, teaching patients prompting healthy lifestyle like eating well, exercising regularly, getting enough sleep and, engaging in religious activities, improving the importance of medication adherence, following habit of multidisciplinary approach of treatment which address biological, psychological and social factors of the illness, appropriate medication, timely dosage adjustment and management of side-effect [19-21]. However in our study area magnitude and the possible factors of relapse among mentally ill patients is not well addressed, so this study tried to address and determine the lifetime prevalence of relapse and possible factors which could be associated with relapse among mentally ill patients who have follow up treatment at Jimma University medical center and this finding will be useful to intervene factors which are responsible for relapse among mentally ill patients in the study area by working with potential stakeholders at the site and national level by preparing national strategies of relapse prevention program among mentally ill patients.

\section{Methods}

\section{Study Area and Period}

This study was conducted at Jimma University medical center psychiatric outpatient clinic from January 10 to February 10, 2019, which was located in southwest Ethiopia and $352 \mathrm{~km}$ away from Addis Ababa, the capital city of Ethiopia.

\section{Study Design}

Institutional-based cross-sectional study design was employed.

\section{Eligibility Criteria}

All mentally ill patients who have follow up treatment at Jimma University medical center and age 18 and above were included in the study whereas patients with acute exacerbations of illness and unable to give information were excluded from the study.

\section{Sample Size Calculation}

The sample size was determined by using single population proportion formula by taking prevalence $(P)$ from the previous studydone in Addis Abeba $(88 \%)$ on relapse and hospitalization in patients with schizophrenia and bipolar disorder [22].

$\mathrm{n}=(\mathrm{Z} \alpha / 2)^{2} \mathrm{p}(1-\mathrm{p}) / \mathrm{d}^{2}$ 
where $\mathrm{n}=$ required sample size, $\mathrm{Z} \alpha / 2=1.96$, $\mathrm{d}=0.05=5 \%, p=0.88, \mathrm{n}=162$.

By adding $10 \%$ non-response rate the final total sample size was 178 .

\section{Sampling Procedure}

A simple random sampling technique was used to get study participants using a computer-generated lottery method taking their list from patient's registration books.

\section{Data Collection Instruments}

For data collection, the following validated tools were used.

World Health Organization Disability Assessment Schedule 2.0, (WHODAS V.2.0)—12 items structured interviewer-administered questioner was used to assess the functional disability of patients with mental illness [23].

To assess internalized stigma, the 24-item Likert scale of the internalized stigma of mental illness (ISMI) scale was used. The scale has a total of 24 items on a 4 -point Likert $(1=$ strongly agree to $4=$ strongly disagree) measure containing four subscales; alienation (6 items), stereotype endorsement (7 items), discrimination experience (5 items) and social withdrawal (6 items).

The scale had a strong internal consistency $(\alpha=0.90)$ and test-retest reliability $(r=0.92)$ have been reported for the internalized stigma of mental illness scale [24].

In the previous study in Ethiopia, the internalized stigma of mental illness scale subscales had reliability values of alienation $=0.84$, stereotype endorsement $=0.73$, discrimination experience $=0.79$, and social withdrawal $=0.77$ [25].

In this study, the stigma score was dichotomized in to low stigma and high stigma if score $\leq 2.5$ and $>2.5$ respectively [26].

Oslo's three items social support scale was used to assess social support, it has a range value of 3-14, which further categorized as "poor social support" 3-8, "moderate social support" 9-11, and "strong social support" 12 and above [27].

The Alcohol, Smoking, and Substance Involvement Screening Test (ASSIST-3.0) were adopted to assess the current alcohol, cigarettes, and khat and cannabis use status of the participants. It developed by WHO to detect psychoactive substance use and related problems in primary care patients with Cronbach alpha (0.73) [28].

Medication nonadherence assessed by asking patients if they were discontinued medications for more than a 3-month duration [29].

Lifetime relapse assessed according to DSM-IV definition of relapse to say a patient had a relapse history the patient should have a history of symptoms exacerbation or more than one admission history which was measured by reviewing the card and interviewing patients [30].

Structured questioners were used to assess the Sociodemographic variables listed in the study variables section.

\section{Data Collection Procedures}

Face to face interviews and document review was used to collect the data for this study. Three Bsc psychiatry nurses and three psychiatry masters supervisors were recruited as data collector after 3-day training was given. Each data collector reviewed the card and recorded the card number of respondents who had completed the questionnaire and share it to all data collectors to avoid redundancy of the participants. The principal investigator and the supervisors checked completeness of the questioners and feedback was given to data collectors on a daily base.

Study Variables

\section{Dependent Variable}

\section{Lifetime relapse.}

\section{Independent Variables}

Socio-demographic related factors include age, gender, educational status, marital status, place of residence, income and current employment status, number of family members, and current living status.

Age and income which we treat as continuous and explained by mean and SD.

Psycho-social factors include social support, functional disability, and self-stigma.

Patient clinical characteristics like current substance use, a current diagnosis of mental illness, age 
onset of the illness, duration of illness, duration of treatment, duration of delay of treatment, admission status, medication adherence, and family history of substance use.

\section{Data Processing and Analysis}

The collected data were cleaned, checked for completeness, coded, and entered into Epi-data version 3.1software and exported to SPSS version 22 statistical software for analysis. Descriptive statistics used to summarize the results.

Bivariate logistic regression used to identify variables that are a candidate for multivariate logistic regression at $P$ value $<0.25$ and multivariate logistic regression were done to identify the independent predictors of lifetime relapse at $P$ value $<0.05$ and the obtained results presented using narration and tables.

\section{Data Quality Assurance}

To assure the data quality the possible maximum sample size with the non-response rate was calculated. Standard and carefully designed questionnaires were used and translated to local languages Afan Oromo and Amharic by two different persons and back translate to English to check the consistency. Moreover, training was given for data collectors and supervisors and data completeness was checked by reviewing collected data and the incomplete questionnaires were excluded from the analysis.

\section{Ethical Considerations}

Ethical clearance was obtained from Jimma University institute of health Institutional Review Board. Written consent was obtained from the study participants and the data was collected at a private place to assured confidentiality of the participants. Participants have the right to stop the interviews at any time if they were not interested. Information obtained was kept confidential and anonymous during all stages of the study.

\section{Results}

Socio-Demographic Characteristics of Respondents

There were 178 samples take part in the study with a $100 \%$ response rate. The majority of the respondents were males $110(61 \%)$, single 103 (57.9\%) in marital status, and living with their family 128 (71.9\%)(Table 1).

The mean age of respondents was 36 with $\mathrm{SD} \pm$ 12 years which ranges from 18 to 85 years and the mean number of family members was 4 with $\mathrm{SD} \pm 2$ which ranges from 0 to 14 . The mean income of respondents per month $522( \pm 200)$ Ethiopian birr.

\section{Clinically Related Factors of Respondents}

Most of the respondents 44(24.7\%) had a diagnosis of major depressive disorder and most respondents 104(58.4\%) had more than two admissions in their lifetime. The mean age onset of illness was 28 with $\mathrm{SD} \pm 12$ years which ranges from 7 to 84 years of age and the mean treatment delay of patients were 1.21 with $\mathrm{SD} \pm 2$ years which ranges from 0 to 16 years. Nearly two-thirds of respondents $116(65.2 \%)$ had moderate social support and 126(70.8\%) respondents had a history of using traditional treatment. From all respondents, $64(36 \%)$ of them had a family history of chat use.

The mean percentage score of disability was $34.8 \%$ and also 54(30.3\%) respondents had a high self-stigma score. More than half of $104(58.4 \%)$ of the respondents were adherent to medication in the last 3 months before the data collection period (Table 2).

\section{The Lifetime Prevalence of Relapse}

The lifetime prevalence of relapse among mentally ill patients in this study was 125 (70.2\%) (Fig. 1).

\section{Factors Associated with Lifetime Relapse}

In the bivariate logistic regression analysis factors such as educational status, occupational status, living status, duration of illness, medication adherence, history of admission, social support, history of using traditional medicine, current substance use, selfstigma, and disability associated with relapse and 
Table 1 Socio-demographic characteristics of respondents who attend the psychiatry out-patient clinic at Jimma University medical center southwest, Ethiopia, $2019(\mathrm{~N}=178)$

\begin{tabular}{|c|c|c|c|}
\hline Variables & Category & Frequency $(\mathrm{N}=178)$ & Percentage $(\%)$ \\
\hline \multirow[t]{2}{*}{ Sex } & Male & 110 & 61.8 \\
\hline & Female & 68 & 38.2 \\
\hline \multirow[t]{4}{*}{ Religion } & Orthodox & 73 & 41.0 \\
\hline & Muslim & 73 & 41 \\
\hline & Protestant & 29 & 16.3 \\
\hline & Catholic & 3 & 1.7 \\
\hline \multirow[t]{5}{*}{ Marital status } & Single & 103 & 57.9 \\
\hline & Married & 51 & 28.7 \\
\hline & Divorced & 13 & 7.3 \\
\hline & Widowed & 8 & 4.5 \\
\hline & Separated & 3 & 1.7 \\
\hline \multirow[t]{5}{*}{ Educational status } & Unable to read and write & 12 & 6.7 \\
\hline & Able to read/write, but no formal education & 4 & 2.2 \\
\hline & Primary level & 65 & 36.5 \\
\hline & Secondary level & 42 & 23.6 \\
\hline & College and above & 55 & 30.9 \\
\hline \multirow[t]{2}{*}{ Occupation } & Jobless & 76 & 42.7 \\
\hline & Have job & 102 & 57.3 \\
\hline \multirow[t]{5}{*}{ Current living condition } & With family & 128 & 71.9 \\
\hline & Living alone & 12 & 6.7 \\
\hline & Living on street & 3 & 1.7 \\
\hline & With relatives/friends & 3 & 1.7 \\
\hline & With wife and kids & 32 & 18.0 \\
\hline
\end{tabular}

were candidate variables for the multivariate logistic regression.

Non adherence $\quad(\mathrm{AOR}=6.35, \quad 95 \% \quad \mathrm{CI}$, 2.524-15.852, $P<0.001)$, high disability score $(\mathrm{AOR}=3.728,95 \% \mathrm{CI}, 1.434-9.687, \quad P=0.007)$ and having single admission history $(\mathrm{AOR}=0.196$, 95\% CI, 0.050-0.761 $P=0.019)$ were independent predictors of relapse in the multivariate logistic regression analysis (Table 3).

\section{Discussion}

This study found that lifetime prevalence of relapse $70.2 \%$ which was higher than the study done in Johannesburg (61.8\%) [4], London (53\%) [31] and India (70\%) [32] and this difference might due to the difference in a study participant, mental health service and literacy. Also, it is higher than the study done in
Jimma (24.6\%) [33], Addis Ababa (43\%) [34] and Butajira (65.9\%) [35] and this might be the difference in sample size, study design, and study setting as well as the diagnosis of patients were not inclusive.

However, this study result was lower than the study done in Addis Ababa Amanuel mental health specialized hospital [22] (87.69\%) among schizophrenic and (88.12\%) among bipolar patients and this might due to the difference in study participants, sample size and diagnosis profile which was selective to the diagnosis schizophrenia and bipolar disorder which had high relapse rate than other types of mental illness.

This study found that non-adherence increase relapse by 6.35 times compared to being adherent which was supported by the study done in the United States of America [36], London [37], India [38], Jordan [39], Jimma [33] and this similar result might be explained by adherence to medication is a pillar for the patient to control symptoms and prevent relapse. 
Table 2 Distribution of clinical related factors among patients who attend the psychiatry out-patient clinic at Jimma University medical center southwest Ethiopia, Jimma 2019, ( $\mathrm{N}=178)$

\begin{tabular}{|c|c|c|c|}
\hline Variable & Category & Frequency & Percentage \\
\hline \multirow[t]{2}{*}{ Disability score } & Low (below mean score) & 113 & 63.5 \\
\hline & High (above mean score) & 65 & 36.5 \\
\hline \multirow[t]{2}{*}{ Stigma } & Low self-stigma $(\leq 2.5)$ & 124 & 69.7 \\
\hline & High self-stigmat $(>2.5)$ & 54 & 30.3 \\
\hline \multirow[t]{10}{*}{ Current psychiatry diagnosis } & Brief psychotic & 12 & 6.7 \\
\hline & Schizoaffective & 8 & 4.5 \\
\hline & Schizophreniform & 7 & 3.9 \\
\hline & Schizophrenia & 56 & 31.5 \\
\hline & Delusional disorder & 3 & 1.7 \\
\hline & Bipolar disorder & 39 & 21.9 \\
\hline & Major depressive disorder & 44 & 24.7 \\
\hline & Post-traumatic stress disorder & 4 & 2.2 \\
\hline & Generalized anxiety disorder & 4 & 2.2 \\
\hline & others (adjustment, Dementia, due to Epilepsy, Somatoform) & 1 & 0.6 \\
\hline \multirow[t]{3}{*}{ History of lifetime admission } & No admission & 42 & 23.5 \\
\hline & Single admission & 32 & 17.9 \\
\hline & Two and above & 104 & 58.4 \\
\hline \multirow[t]{3}{*}{ Duration of illness } & $<5$ years & 75 & 42.1 \\
\hline & $5-10$ years & 54 & 30.3 \\
\hline & $>10$ years & 49 & 27.5 \\
\hline \multirow[t]{3}{*}{ Social support } & Poor social support & 36 & 20.2 \\
\hline & Moderate social support & 116 & 65.2 \\
\hline & Strong social support & 26 & 14.6 \\
\hline \multirow[t]{2}{*}{ History of traditional treatment } & Yes & 126 & 70.8 \\
\hline & No & 52 & 29.2 \\
\hline \multirow[t]{2}{*}{ Medication adherence } & Adherence & 104 & 58.4 \\
\hline & Non-adherence & 74 & 41.6 \\
\hline \multirow[t]{2}{*}{ Current Substance use } & Non-user & 85 & 47.8 \\
\hline & User & 93 & 52.2 \\
\hline
\end{tabular}

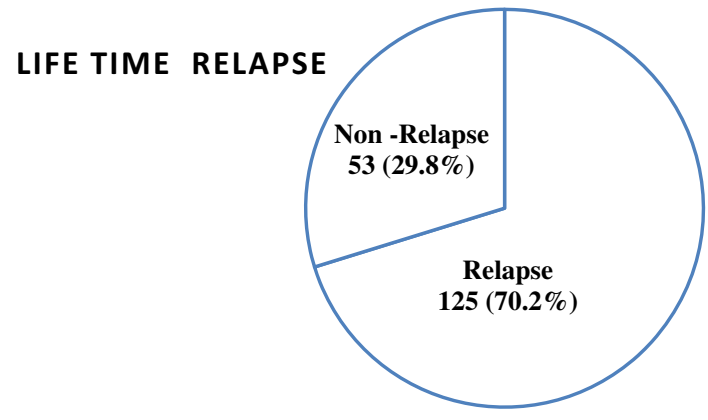

Fig. 1 Lifetime relapse of patients with mental illness at JUMC southwest Ethiopia, $(\mathrm{N}=178), 2019$
This study found that high disability score increases the chance of relapse by 3.72 times compared to having low disability score, and this study finding was supported by the world health organization mental illness prevention report [40], and this supporting evidence might be explained by patients current functionality status including their personal care and participation in a society which contributes for the stigma and self-esteem of patents associated with their current functionality and contribute for relapse.

This study found that those respondents who had a history of single-admission history had 0.019 times 
Table 3 Factors associated with relapse among patients who attend the psychiatry out-patient clinic at Jimma University medical center southwest Ethiopia, Jimma 2019, ( $\mathrm{N}=178)$

\begin{tabular}{|c|c|c|c|c|c|c|}
\hline \multirow[t]{2}{*}{ Variables } & \multicolumn{2}{|c|}{ Bivariate logistic regression } & \multicolumn{4}{|c|}{ Multivariate logistic regression } \\
\hline & Sig & COR & Sig & AOR & $95 \% \mathrm{CI}$ & \\
\hline Unable to read and write & 1 & & & & & \\
\hline Attending secondary school & $.148 *$ & .545 & .104 & .400 & .132 & 1.209 \\
\hline Attending more than secondary school & $.083^{*}$ & .453 & .136 & .410 & .127 & 1.324 \\
\hline With job & $.127 *$ & 1.683 & .114 & 2.160 & .830 & 5.617 \\
\hline Without job & 1 & & & & & \\
\hline Living with family & 1 & & & & & \\
\hline Living in the street & $.125^{*}$ & .302 & .435 & .376 & .032 & 4.396 \\
\hline$<5$-year duration of illness & 1 & & & & & \\
\hline $5-10$ year duration of illness & $.094 *$ & .513 & .074 & .400 & .146 & 1.092 \\
\hline$>10$-year duration of illness & $.226 *$ & 1.806 & .372 & 1.684 & .537 & 5.284 \\
\hline Non-adherent & $.000 *$ & 7.591 & $.000 * *$ & 6.325 & 2.524 & 15.852 \\
\hline Adherent & 1 & & & & & \\
\hline No-admission & 1 & & & & & \\
\hline Single admission & $.002 *$ & .178 & $.019 * *$ & .196 & .050 & .761 \\
\hline Two and above admission & $.087 *$ & .343 & .553 & .633 & .139 & 2.875 \\
\hline Poor social support & 1 & & & & & \\
\hline Moderate social support & $.169^{*}$ & 2.188 & .482 & 2.014 & 0.354 & 3.567 \\
\hline Strong social support & .413 & 1.446 & & & & \\
\hline Having history traditional treatment use & 1 & & & & & \\
\hline No history of traditional treatment use & $.020^{*}$ & 2.247 & .181 & 1.912 & .740 & 4.939 \\
\hline Current substance user & $.125 *$ & .602 & .415 & 1.427 & .607 & 3.356 \\
\hline Not user & 1 & & & & & \\
\hline Low disability score & 1 & & & & & \\
\hline High disability score & $.000^{*}$ & 8.286 & $.007 * *$ & 3.728 & 1.434 & 9.687 \\
\hline Low self-stigma score & 1 & & & & & \\
\hline High self-stigma score & $.005^{*}$ & 3.275 & .713 & 1.216 & .428 & 3.458 \\
\hline
\end{tabular}

The final model explained $69.4 \%$ of the variance of relapse

$1=$ reference

*Significant at $p$ value $<0.25$

**Variables which are independent predictors of relapse of mentally ill patients in the multivariate logistic regression analysis at $P$ value $<0.05$ and $95 \%$ confidence interval

less likely for relapse as compared those with no admission history and this study finding was supported by the study done in Norway [41] and united kingdom [42] which indicate during the first contact of treatment, especially for patients with comorbid substance use and psychosocial problem inpatient service, was a pillar for preventing relapse because in-patient service allows clinicians for assessing factors related to the illness and planning effective treatment according to the settled diagnosis. In this study, this might be because more than half of respondents had current substance use history which might contribute to relapse.

\section{Limitations of the Study}

There were some limitations in this study as the study used a cross-sectional study design, no conclusions 
can be drawn regarding causality and alternative explanations of the findings and cannot be ruled out. Another limitation of the study could be that as the information obtained through interviewer-administered questioner so that responses might be prone to social desirability bias, interviewer bias, and recall bias.

\section{Conclusions}

Finally, the lifetime prevalence of relapse in this study is high. non-adherence, disability score, and the number of admissions were independent predictors of relapse of patients with mental illness. Therefore, while giving treatment, it is good to give psychoeducation and teaching patients and relatives about adherent to medications and how much it is important to prevent relapse and enhancing the functioning of patients which also decreases the disability score of patients which results in having low relapse rate. Thus, if mentally ill patients become adherent to medication the number of hospital admissions will be decreased and which return, might be helpful to decrease the number of relapses. Finally, the author suggests for future researchers to do interventional study by including both patients and relatives to enrich factors associated with relapse.

Acknowledgements We would like to thank the clients who participated in the study and Jimma University.

Author's Contribution CK and LA carried out the manuscript from its conception, analysis, interpretation of data, drafted the manuscript, and review of the manuscript. All authors read and approved the final draft of the manuscript.

Funding The study400 was supported financially by Jimma University Institute of 401 Health.

Availability of Data and Materials The datasets used/or analyzed during the current study is available from the corresponding author on reasonable request.

\section{Compliance with Ethical Standards}

Conflict of interests The authors declare that they have no conflict of interests.

Ethical Approval Ethical clearance was obtained from the ethical review board of Jimma University Institute of Health.
Consent to Participate Written consent was obtained from the study participants. Confidentiality and privacy were maintained during data collection, analysis, and reporting.

Open Access This article is licensed under a Creative Commons Attribution 4.0 International License, which permits use, sharing, adaptation, distribution and reproduction in any medium or format, as long as you give appropriate credit to the original author(s) and the source, provide a link to the Creative Commons licence, and indicate if changes were made. The images or other third party material in this article are included in the article's Creative Commons licence, unless indicated otherwise in a credit line to the material. If material is not included in the article's Creative Commons licence and your intended use is not permitted by statutory regulation or exceeds the permitted use, you will need to obtain permission directly from the copyright holder. To view a copy of this licence, visit http://creativecommons.org/licenses/by/4.0/.

\section{References}

1. Metrics GH. Global, regional, and national incidence, prevalence, and years lived with disability for 354 diseases and injuries for 195 countries and territories, 1990-2017: a systematic analysis for the Global Burden of Disease Study 2017. Lancet Psychiatry. 2018;392:1990-2017.

2. World Health Organization, Geneva, 2011.

3. Grace R, Onaiza Q, Natasha SJE. Mental health for global prosperity. London Sch Hyg Trop Med. 2019; (January):1-3.

4. Kazadi NJB, Moosa MYH, Jeenah FY. Articles factors associated with relapse in schizophrenia. Soc Anxiety J Psychiatry. 2008;14(2):52-3.

5. Swendsen J. Disorder. Am J Psychiatry. 1995;152:1635-40.

6. Doering S, Mutter E, Kopcke W, Pietzcker A, Qaebel W, Linden M, et al. Predictors of relapse and rehospitalization in schizophrenia and schizoaffective disorder. Schizophr Bull. 1998;24(1):87-98.

7. Dunn T. The association between medication adherence in mental illness and substance use disorder relapse in patients with dual diagnosis. Subst Abuse Addict J 2018; 100-105.

8. Vaughn BCE. The influence of family and social factors on the course of psychiatric illness. $\mathrm{Br} \mathrm{J}$ Psychiatry. 1976;129:125-37.

9. Baguma C, Ashaba S. Portrayals of mental illness, treatment, and relapse and their effects on the stigma of mental illness: population-based, randomized survey experiment in rural Uganda. PLoS ONE Med. 2018;4:1-19. https://doi. org/10.1371/journal.pmed.1002908.

10. Rollins AL, O'Neill SJ, Davis KE, Devitt TS. Substance abuse relapse and factors associated with relapse in an inner-city sample of patients with dual diagnoses. Psychiatr Serv. 2005;56(10):1274-81.

11. Butzlaff RL, Hooley JM. Expressed emotion and psychiatric relapse. Arch Gen Psychiatry. 1998;55(6):547-52.

12. Di S, Rachel C, Mallikarjun P. The relapse rate and predictors of relapse in patients with first-episode psychosis following discontinuation of antipsychotic medication. 
Early Interv Psychiatry. 2018;12(5):893-9. https://doi.org/ 10.1111/eip.12385 Epub 2016 Oct 13.

13. Hayes JF, Osborn DPJ, Lundin A, Dalman C. Psychiatric hospitalization following antipsychotic medication cessation in first-episode psychosis. $\mathrm{J}$ Psychopharmacol. 2019;33(4):532-4. https://doi.org/10.1177/ 0269881119827883.

14. Camacho-Gomez M, Castellvi P. Effectiveness of family intervention for preventing relapse in first-episode psychosis until 24 months of follow-up: a systematic review with meta-analysis of randomized controlled trials. Schizophr Bull. 2018;46(1):98-109. https://doi.org/10.1093/ schbul/sbz038.

15. Takeuchi H, Siu C, Remington G, Fervaha G, Zipursky RB, Foussias G. Does relapse contribute to treatment resistance? Antipsychotic response in first- vs. Second-episode schizophrenia. Neuropsychopharmacology. 2018;2:1-7. https://doi.org/10.1038/s41386-018-0278-3.

16. Curto M, Masters G, Girardi P. Factors associated with costs of hospitalization of severely mentally ill bipolar disorder: open access factors associated with costs of hospitalization of severely mentally ill patients. J Bipolar Disord. 2016;2:1-4.

17. Thomas P. Relapse: causes and consequences. Encephale J. 2013;39:S79-82. 7006(13)70100-3.

18. C-h T. One-year post-hospital medical costs and relapse rates of bipolar disorder patients in Taiwan: a populationbased study. Bipolar Disord. 2010;12(8):859-65. https:// doi.org/10.1111/j.1399-5618.2010.00878.

19. Rice S, Gleeson J, Davey C, Hetrick S, Parker A, Lederman $\mathrm{R}$, et al. Original article moderated online social therapy for depression relapse prevention in young people: a pilot study of a ' next generation ' online intervention. Early Interv Psychiatry. 2018;12:613-25.

20. Flint AJ, Meyers BS, Rothschild AJ, Whyte EM, Alexopoulos GS, Rudorfer MV, et al. Effect of continuing olanzapine vs placebo on relapse among patients with psychotic depression in remission the STOP-PD II randomized clinical trial. JAMA Psychiatry. 2019;322(7):622-31.

21. Johnson S, Lamb D, Marston L, Osborn D, Mason O, Henderson C, et al. Peer-supported self-management for people discharged from a mental health crisis team: a randomized controlled trial. Lancet. 2018;392(10145):409-18. https://doi.org/10.1016/S0140-6736(18)31470-3.

22. Ayano G, Duko B. Relapse, and hospitalization in patients with schizophrenia and bipolar disorder at the St Amanuel Mental Specialized Hospital, Addis Ababa, Ethiopia: a comparative quantitative cross-sectional study. Neuropsychiatr Dis Treat. 2017;13:1527-31.

23. Habtamu K, Medhin G, Selamu M, Tirfessa K, Hanlon C. Functional impairment among people diagnosed with depression in primary healthcare in rural Ethiopia: a comparative cross-sectional study. Int J Ment Health Syst. 2019. https://doi.org/10.1186/s13033-019-0305-8.

24. Goleman D, Boyatzis R, Mckee A. Depression self-stigma as a mediator of the relationship between depression severity and avoidance. J Chem Inf Model. 2019;53(9):1689-99.
25. Girma E, Tesfaye M, Froeschl G, Möller-Leimkühler AM, Dehning S, Müller N. Facility based cross-sectional study of self-stigma among people with mental illness: towards patient empowerment approach. Int J Ment Health Syst. 2013;7(21):1-8. https://doi.org/10.1186/1752-4458-7-21.

26. Tanabe Y, Hayashi K, Ideno Y. The internalized stigma of mental illness (ISMI) scale: validation of the Japanese version. BMC Psychiatry. 2016. https://doi.org/10.1186/ s12888-016-0825-6.

27. Abiola T, Udofia O, Zakari M. Psychometric properties of the 3-item Oslo social support scale among clinical students of Bayero University Kano, Nigeria. Malays J Psychiatry. 2013;22:32-41.

28. Group WAW. The alcohol, smoking, and substance involvement screening test (ASSIST): development, reliability and feasibility. Addict J Psychiatry. 2002;97:1183-94.

29. Morken G, Widen JH, Grawe RW. Rehospitalisation in recent-onset schizophrenia. BMC Psychiatry. 2008;7(8):1-7.

30. Arlington. Diagnostic and statistical manual of mental disorders. America; 2013, pp 153-67.

31. Lam DH, Watkins ER, Hayward P, Bright J, Wright K, Kerr $\mathrm{N}$, et al. A randomized controlled study of cognitive therapy for relapse prevention for bipolar affective disorder. Arch Gen Psychiatry. 2003;60:145-52.

32. Olfson M. Cost of relapse in schizophrenia. Schizophr Bull Oxf. 1995;21(3):419-29.

33. Fikreyesus M, Soboka M, Feyissa GT. Psychotic relapse and associated factors among patients attending health services in Southwest Ethiopia: a cross-sectional study. BMC Psychiatry. 2016;16(354):5-7. https://doi.org/10. 1186/s12888-016-1076-2.

34. Weret ZS, Mukherjee R. Prevalence of relapse and associated factors in patient with schizophrenia at Amanuel Mental Specialized Hospital, Addis Ababa, Ethiopia: institution based cross-sectional study. Int $\mathbf{J}$ Interdiscip Multidiscip Stud. 2014;2(1):184-92.

35. Fekadu A, Kebede D, Alem A, Fekadu D, Mogga S, Negash A, et al. Clinical outcome in bipolar disorder in a community-based follow-up study in Butajira, Ethiopia. Acta Psychiatry Scand. 2006;114:426-34.

36. Gopinath S, Katon WJ, Russo JE, Ludman EJ. Clinical factors associated with relapse in primary care patients with chronic or recurrent depression. J Affect Disord. 2007;101(3):57-63.

37. Schoeler T, Petros N, Di Forti M, Klamerus E, Foglia E, Murray R, et al. Poor medication adherence and risk of relapse associated with continued cannabis use in patients with first-episode psychosis: a prospective analysis. Lancet Psychiatry. 2017;4(8):627-33. https://doi.org/10.1016/ S2215-0366(17)30233-X.

38. Chaurotia VK, Verma KK, Baniya GC. A study of psychosocial factor related with relapse in schizophrenia. J Dent Med Sci. 2016;15(4):26-34.

39. Yassin S, Ali AA. Predictors of non-adherence in patients taking psychotropic medication and predictors of non-adherence in patients taking psychotropic medication and suggestions to improve. J Heal Med Nurs. 2019;38:73-5.

40. Hosman J-L\& S. Prevention of Mental Disorders Geneva; 2005. 
41. Wessel H, Wenaas M, Nordfjærn T. Addictive behaviors relapse after inpatient substance use treatment: a prospective cohort study among users of illicit substances. Addict Behav. 2019;90:222-8. https://doi.org/10.1016/j.addbeh. 2018.11.008.

42. Werbeloff N, Chang C, Broadbent M, Hayes JF, Stewart R, Osborn DPJ. Admission to acute mental health services after contact with crisis resolution and home treatment teams: an investigation in two large mental health-care providers. Lancet Psychiatry. 2015;4(1):49-56. https://doi.org/10. 1016/S2215-0366(16)30416-3.

Publisher's Note Springer Nature remains neutral with regard to jurisdictional claims in published maps and institutional affiliations. 